\title{
Release of Mitochondrial Cytochrome $C$ in Both Apoptosis and Necrosis Induced by $\beta$-Lapachone in Human Carcinoma Cells
}

\author{
You-Zhi Li, ${ }^{1}$ Chiang J. Li, ${ }^{1}$ Antonio Ventura Pinto, ${ }^{2}$ and \\ Arthur B. Pardee ${ }^{1}$ \\ ${ }^{1}$ Division of Cell Growth and Regulation, Dana-Farber Cancer \\ Institute, and Department of Biological Chemistry and Molecular \\ Pharmacology, Harvard Medical School, Boston, Massachusetts, U.S.A. \\ ${ }^{2}$ Centro de Ciencias Dasaude, Bioc H-Ilna de Cidade Universitaria, \\ 21941-590 Rio de Janeiro, Brazil
}

Communicated by A. Pardee. Accepted February 18, 1999.

\begin{abstract}
Background: There are two fundamental forms of cell death: apoptosis and necrosis. Molecular studies of cell death thus far favor a model in which apoptosis and necrosis share very few molecular regulators. It appears that apoptotic processes triggered by a variety of stimuli converge on the activation of a member of the caspase family, such as caspase 3 , which leads to the execution of apoptosis. It has been suggested that blocking of caspase activation in an apoptotic process may divert cell death to a necrotic demise, suggesting that apoptosis and necrosis may share some upstream events. Activation of caspase is preceded by the release of mitochondrial cytochrome $\mathrm{C}$.

Materials and Methods: We first studied cell death induced by $\beta$-lapachone by MTT and colonyformation assay. To determine whether the cell death induced by $\beta$-lapachone occurs through necrosis or apoptosis, we used the PI staining procedure to determine the sub-Gl fraction and the Annexin-V staining for externalization of phophatidylserine. We next compared the release of mitochondrial cytochrome $\mathrm{C}$ in apoptosis and necrosis. Mitochondrial cytochrome $\mathrm{C}$ was determined by Western blot analysis. To investigate changes in mitochondria that resulted in cytochrome $\mathrm{C}$ release, the mitochondrial membrane potential (delta psi) was analyzed by the accumulation of rhodamine 123, a membrane-permeant cationic fluorescent dye. The activation of caspase in apoptosis and necrosis were measured by using a profluorescent substrate for caspase-like proteases, PhiPhiLuxG6D2. Results: $\beta$-lapachone induced cell death in a spec-
\end{abstract}

trum of human carcinoma cells, including nonproliferating cells. It induced apoptosis in human ovary, colon, and lung cancer cells, and necrotic cell death in four human breast cancer cell lines. Mitochondrial cytochrome $\mathrm{C}$ release was found in both apoptosis and necrosis. This cytochrome $C$ release occurred shortly after $\beta$-lapachone treatment when cells were fully viable by trypan blue exclusion and MTT assay, suggesting that cytochrome $C$ release is an early event in $\beta$-lapachone induced apoptosis as well as necrosis. The mitochondrial cytochrome $C$ release induced by $\beta$-lapachone is associated with a decrease in mitochondrial transmembrane potential (delta psi). There was activation of caspase 3 in apoptotic cell death, but not in necrotic cell death. This lack of activation of CPP 32 in human breast cancer cells is consistent with the necrotic cell death induced by $\beta$-lapachone as determined by absence of sub-Gl fraction, externalization of phosphatidylserine.

Conclusions: $\beta$-lapachone induces either apoptotic or necrotic cell death in a variety of human carcinoma cells including ovary, colon, lung, prostate, and breast, suggesting a wide spectrum of anti-cancer activity in vitro. Both apoptotic and necrotic cell death induced by $\beta$-lapachone are preceded by a rapid release of cytochrome $C$, followed by the activation of caspase 3 in apoptotic cell death but not in necrotic cell death. Our results suggest that $\beta$-lapachone is a potential anti-cancer drug acting on the mitochondrial cytochrome C-caspase pathway, and that cytochrome $C$ is involved in the early phase of necrosis. 


\section{Introduction}

There are two morphologically distinct forms of cell death: apoptosis and necrosis. Mounting evidence indicates that apoptosis rather than necrosis predominates after many cytotoxic injuries (1). Apoptosis is characterized by chromosomal condensation and breakage detected as a sub-Gl fraction on flow cytometry, and by membrane changes exemplified by externalization of phosphatidylserine. Necrosis is characterized by rupture of the plasma membrane and formation of large chromatin clumps (1). The molecular processes of necrosis are less well investigated than those of apoptosis.

Molecular studies of cell death thus far favor a model in which apoptosis and necrosis share very few molecular regulators. It appears that apoptotic processes triggered by a variety of stimuli converge on the activation of a member of the caspase family, such as caspase 3 , which leads to the execution of apoptosis (2). Activation of this caspase has been shown to be preceded by the release of cytochrome $\mathrm{C}$ from mitochondria into the cytoplasm (3), where it interacts with Apaf-1, an analog of ced-4, leading to caspase activation. It has been suggested that blocking of caspase activation in an apoptotic process may divert cell death to a necrotic demise (4), indicating that apoptosis and necrosis may share some upstream events.

We and others have reported that $\beta$-lapachone (3,4-dihydro-2,2-dimethyl-2H-naphthol[1,2-b] pyran-5,6-dione), a plant product $(5,6)$, triggers apoptosis in human prostate cancer cells, including hormone refractory cells, and in leukemia HL-60 cells $(7,8)$. We also observed cell death in other human cancer cells including those from ovary, colon, lung, and breast cancers (7). The recent advances in concepts and methodologies for the study of apoptosis have allowed us to investigate the nature and the mechanism of cell death induced by $\beta$-lapachone. Unlike camptothecin, there is no increase of wild-type p53 in $\beta$-lapachoneinduced cell death processes (8), nor does the presence of mutant p53 affect sensitivity to $\beta$-lapachone, suggesting a different mechanism.

In this study, we found that $\beta$-lapachone induces either apoptotic or necrotic cell death in a variety of human carcinoma cells including ovary, colon, lung, prostate, and breast, suggesting a wide spectrum of anti-cancer activity of $\boldsymbol{\beta}$-lapachone in

Address correspondence and reprint requests to: $\mathrm{Dr}$. Chiang J. Li, Dana-Farber Cancer Institute, D612, 44 Binney St., Boston, MA 02115, U.S.A. Phone: 617-632-4687; Fax: 617632-4680; E-mail: cjli@mbcrr.harvard.edu vitro. Both apoptotic and necrotic cell death induced by $\beta$-lapachone are preceded by a rapid release of cytochrome $C$, followed by the activation of caspase 3 in apoptotic cell death but not in necrotic cell death. Our results suggest that $\beta$-lapachone is a potential anti-cancer drug acting on the mitochondrial cytochrome $\mathrm{C}$-caspase pathway, and that cytochrome $\mathrm{C}$ is involved in the early phase of necrosis.

\section{Materials and Methods}

\section{Chemicals}

$\beta$-lapachone was kindly provided by Dr. A. Matter (CIBA-GEIGY, Switzerland) or semi-synthesized by us. It was dissolved at $20 \mathrm{mM}$ concentration in dimethyl sulfoxide (DMSO), aliquoted, and stored at $-20^{\circ} \mathrm{C}$.

\section{Cell Cultures}

All cell lines used in this study were obtained from the American Type Culture Collection (Rockville, MD) unless specified otherwise. Cells were maintained at $37^{\circ} \mathrm{C}$ in $5 \% \mathrm{CO}_{2}$ in complete humidity. Human breast cancer cell lines, MCF-7, and 21 MT, 21 PT, and 21 NT (kindly provided by Dr. R. Sager, Dana-Farber Cancer Institute, Boston) were cultured in minimum essential medium (MEM) alpha medium (Life Technologies, Gaithersburg, MD), supplemented with $10 \%$ fetal calf serum (FCS), 2 $\mathrm{mM}$ L-glutamine, and $1 \mathrm{mg} / \mathrm{ml}$ insulin. $\mathrm{AD} 2780 \mathrm{~s}$ (human ovary carcinoma), a generous gift from Dr. K. J. Scanlon (City of Hope Medical Center, Duarte, CA), human colon adenocarcinoma cell lines SW1116, HT-29, and DLD, a human lung carcinoma cell line (G480), and human prostate tumor cells PC-3, DU145, and LNCaP were cultured in Dulbecco's modified Eagle's medium (DMEM; Life Technologies) supplemented with $10 \%$ FCS and 2 mM L-glutamine.

\section{Colony Formation Assay}

Exponentially growing cells were seeded at 1000 cells/dish in 6-well plates and allowed to attach for $48 \mathrm{hr}$. $\beta$-lapachone was added directly to dishes in $<5 \mu \mathrm{l}$ of concentrated solution (corresponding to a final DMSO concentration of $<0.1 \%$ ). Control plates received the same volume of DMSO alone. After 1 to $4 \mathrm{hr}$ cells were rinsed and medium was added. Cultures were observed daily for 10 to 20 days, and then were fixed and stained with modified Wright-Giemsa 
Stain (Sigma, St. Louis, MO). Colonies of greater than 30 cells were scored as survivors.

\section{Cell Death Assay}

Cell death was determined by the MTT assay, or by trypan blue exclusion as indicated. Briefly, cells were plated in a 96-well plate at 10,000 cells/well, cultured for $48 \mathrm{hr}$ in complete growth medium, then treated with $\beta$-lapachone for $4 \mathrm{hr}$ and cultured with drug-free medium for $24 \mathrm{hr}$. MTT solution was added to the culture medium, and after $2 \mathrm{hr}$ optical density was read with an ELISA reader. For the trypan blue exclusion assay, cells were cultured and treated in the same way. They were harvested and trypan blue dye solution was added to the cell suspension. Total cell counts and viable cell number were determined with a hemocytometer.

\section{Apoptosis and Necrosis Assay}

Apoptosis was determined by two independent assays. One determined the sub-Gl fraction by propodium iodide (PI) staining of nuclei as described previously (9). The other measured the membrane changes determined by the externalization of phosphatidylserine (10). Briefly, cells were treated with $\beta$-lapachone for $4 \mathrm{hr}$, incubated in drug-free medium for $20 \mathrm{hr}$, harvested, washed in phosphate-buffered saline (PBS), resuspended in binding buffer, incubated with annexin V-FITC, and analyzed by flow cytometry. By contrast, necrotic cells were analyzed by MTT and trypan blue exclusion tests for confirming cell death and the lack of the aforementioned apoptotic features.

\section{Preparation of the Cytosol S-100 Fraction from Cancer Cells}

Cells were treated with $\beta$-lapachone for $\mathrm{l} \mathrm{hr}$, and harvested for the preparation of S-100 fraction (11). Briefly, cells were harvested by centrifugation and the cell pellet was resuspended in 5 vol of ice-cold buffer A (20 mM Hepes- $\mathrm{KOH}$ [pH 7.5], 10 $\mathrm{mM} \mathrm{KCl}, 1.5 \mathrm{mM} \mathrm{MgCl}, 1 \mathrm{mM}$ sodium EDTA, 1 mM sodium EGTA, $1 \mathrm{mM}$ dithiothreitol [DTT], and $0.1 \mathrm{mM}$ phenylmethylsulfonyl fluoride [PMSF]), supplemented with protease inhibitors $(5 \mu \mathrm{g} / \mathrm{ml}$ pepstatin A, $10 \mu \mathrm{g} / \mathrm{ml}$ leupeptin, $2 \mu \mathrm{g} / \mathrm{ml}$ aprotinin). Cells were sheared 15 times in a Dounce homogenizer with pestle. The nuclei were centrifuged at $1000 \times g$ for $10 \mathrm{~min}$ at $4^{\circ} \mathrm{C}$. The supernatant was further centrifuged at $10^{5} \times g$ for $1 \mathrm{hr}$ in a Beckman SW 28 rotor, and the resulting super- natant (S-100 fraction) was used for cytochrome C analysis.

\section{Mitochondrial Membrane Potential Assay}

Cells were pretreated with rhodamine 123 for 10 min at $37^{\circ} \mathrm{C}$. Cells were then washed with serum-free culture medium and were cultured overnight prior to treatment with $\beta$-lapachone or DMSO. Cells were analyzed by fluorescence microscopy or by flow cytometry.

\section{Western Blot Analysis}

The enhanced chemiluminescence (ECL) assay system was used to determine the cytochrome $\mathrm{C}$ released from mitochondria (S-100 fraction). Briefly, S-100 samples (15 $\mu \mathrm{g}$ protein per sample) were electrophoresed in a sodium dodecyl sulfate-polyacrylamide gel and then electrophoretically transferred to a nitrocellulose membrane. The blot was blocked, washed, and incubated with cytochrome $\mathrm{C}$ antibody (Pharmingen, San Diego, CA) at 1:1000 dilution. The filter was then incubated with a secondary antibody that was conjugated with horseradish peroxidase. Finally, the filter was developed with detection reagents (RPN 2109; Amersham) and exposed to a hyperfilm-ECL (RPN 2103).

\section{Caspase Analysis}

The activity of caspase 3 was determined by using a profluorescent substrate for caspase-like proteases, PhiPhiLux-G6D2 (OncoImmunin, College Park, MD) (12). Briefly, cells were treated with $\beta$-lapachone for $4 \mathrm{hr}$, and incubated in drug-free medium for $20 \mathrm{hr}$. Cells were harvested, aliquoted into $1.5 \mathrm{ml}$ microcentrifuge tubes, and incubated at $37^{\circ} \mathrm{C}$ with the substrate at $10 \mu \mathrm{M}$ for $60 \mathrm{~min}$. Intracellular caspase 3 activity was determined by flow cytometry.

\section{Results}

$\beta$-lapachone Induces Loss of Survival in a Spectrum of Human Carcinoma Cells

Human carcinoma cell lines of different histotypes were used to determine survival by colony formation assay. $\beta$-lapachone decreased cell survival in a variety of human carcinoma cell lines (Fig. 1), through induction of cell death as determined by the MTT assay and the trypan blue exclusion assay (data not shown). Human ovary carcinoma cells 

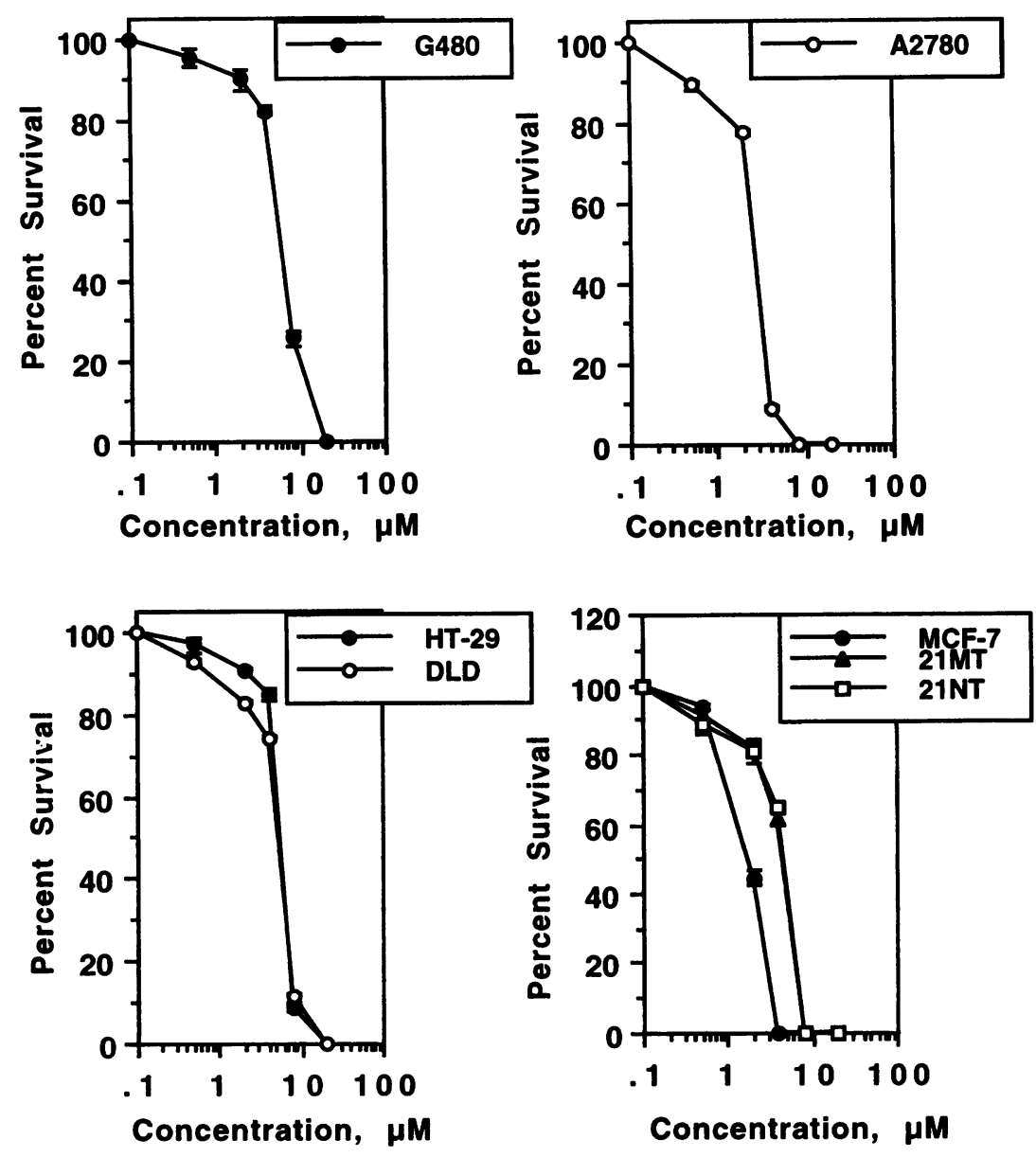

Fig. 1. Inhibition of colony formation by $\beta$-lapachone in human carcinoma cells. Cell survival was determined by colony-formation assay as described in Materials and Methods. Cell lines used include G480 (lung cancer), A2780 (ovary cancer), HT-29 and DLD (colon cancer), MCF-7, $21 \mathrm{MT}$, and 21 NT (breast cancer).

(AD2780s) were very sensitive to $\beta$-lapachone $\left(\mathrm{IC}_{50}, 2 \mu \mathrm{M}\right)$. No cross-resistance was observed in cisplatin-resistant human ovary cells (AD278DDP), suggesting little overlap in the modes of drug action. The survival of human colon adenocarcinoma cells was decreased by $\beta$-lapachone with varied sensitivity among different cell lines. While SW116 was not significantly inhibited by up to $128 \mu \mathrm{M}$ $\beta$-lapachone, HT-29 and DLD were relatively sensitive with $\mathrm{IC}_{50}$ around $5 \mu \mathrm{M}$. $\beta$-lapachone also inhibited the survival of human lung cancer cell line $\mathrm{G} 480\left(\mathrm{IC}_{50}, 4 \mu \mathrm{M}\right)$. Notably, colon cancer cells DLD with mutant $\mathrm{p} 53$, like prostate cancer DU145, are sensitive to $\beta$-lapachone. Human breast cancer cells (21 MT, MCF-7, 21 PT, 21 NT) were also relatively sensitive to $\beta$-lapachone $\left(\mathrm{IC}_{50}, 2 \mu \mathrm{M}\right)$.

To test if cell death induced by $\beta$-lapachone is dependent on cell proliferation, we cultured human LNCaP prostate cells in androgen- and serum-starved conditions before drug treatment. After $96 \mathrm{hr}$ of culture under the starved condition, growth arrest of these cells was confirmed by flow-cytometric analysis. The death of LNCaP cells by $\beta$-lapachone was not affected by cell cycle arrest (data not shown). Androgen refractory DU145 and PC-3 cells grown to confluency and serum starved for $72 \mathrm{hr}$ were equally sensitive to $\beta$-lapachone (data not shown). These results suggest that induction of cell death by $\beta$-lapachone is through a cell death circuit rather than being secondary to proliferation blockage.

\section{Induction of Apoptosis and Necrosis by $\beta$-Lapachone}

Among human carcinoma cell lines, DNA laddering was previously observed only in human prostate cancer cells (7). To determine whether death of other cells induced by $\beta$-lapachone occurs through necrosis or apoptosis, we used the PI staining procedure to determine the sub-Gl fraction, as a test for apoptosis (7-9). As shown in Figure 2A, sub-Gl cells were detected in human ovary, colon, and lung cancer cells. We determined externalization of phosphatidylserine, as measured by Annexin V staining (10), in these cells. As shown in Figure 2B, the percentage of Annexin V-positive 
A

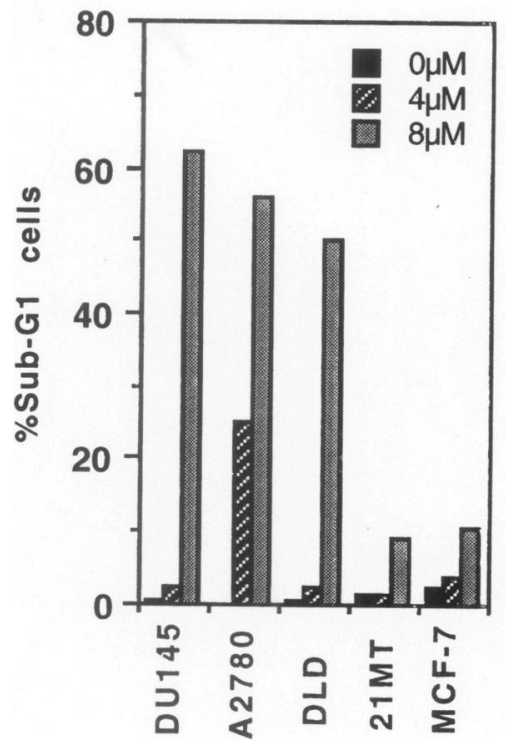

B

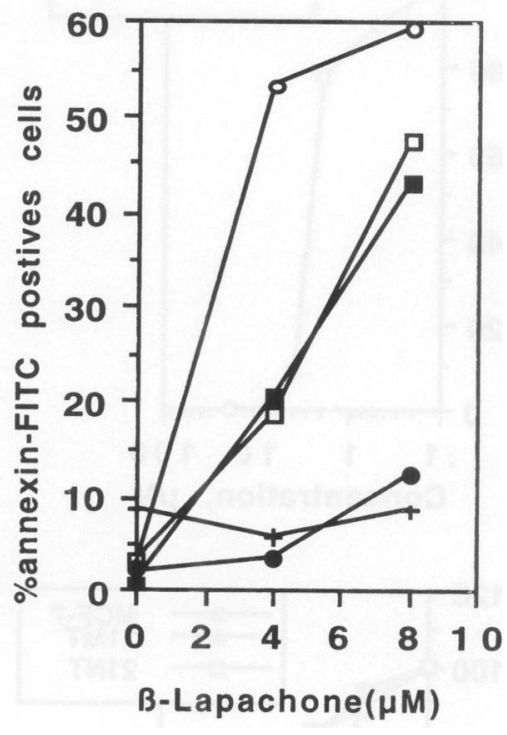

Fig. 2. Cell death induced by $\beta$-lapachone displays either apoptotic or necrotic features. Human ovary, breast, and colon cancer cells were treated with $\beta$-lapachone $0 \mu \mathrm{M}$ (DMSO), $4 \mu \mathrm{M}$, or $8 \mu \mathrm{M}$ for $4 \mathrm{hr}$, followed by incubation in drug-free medium for $20 \mathrm{hr}$ before they were subjected to flow-cytometric analysis after staining with propidium iodide for quantitating the sub-Gl fraction (A), or for the analysis of externalization of phosphatidylserine (B), as measured by Annexin V staining. $\square$, DU 145; O, A2780; $\square$, DLD; $\bullet, M C F$, $+21 \mathrm{MT}$. cells correlated with sub-Gl fractions, suggesting that $\beta$-lapachone induced apoptotic cell death in these cell lines.

Four different human breast cancer cells were used in our study: MCF-7, 21 MT, $21 \mathrm{PT}$, and 21 NT. Under the conditions in which $\beta$-lapachone induced significant cell death, as determined by MTT assay and trypan blue exclusion assay (data not shown), no significant sub-Gl fraction was detected in all four breast cancer cell lines at $24 \mathrm{hr}$ after drug treatment (Fig. 2A). Furthermore, there was no significant Annexin V staining, although cell death occurred (Fig. 2B). These results suggest that $\beta$-lapachone induces necrotic cell death rather than apoptosis in breast cancer cells.

\section{Cell Death Induced by $\beta$-Lapachone Is Preceded by Cytochrome C Release}

One of the upstream events in the apoptotic process is the release of cytochrome $\mathrm{C}$ from mitochondria into the cytoplasm where it engages in a cascade of interactions that lead to the execution stage of apoptosis (3). To determine if $\beta$-lapachone triggers cytochrome $C$ release, cells were analyzed for cytoplasmic cytochrome $\mathrm{C}$ at $\mathbf{l ~ h r}$ after drug treatment. As shown in Figure 3, cytochrome $C$ was released into cytoplasm shortly after $\beta$-lapachone treatment when cells were fully viable by trypan blue exclusion and MTT assay, suggesting that cytochrome $\mathrm{C}$ release is an early event in $\beta$-lapachone-induced apoptosis as well as necrosis.

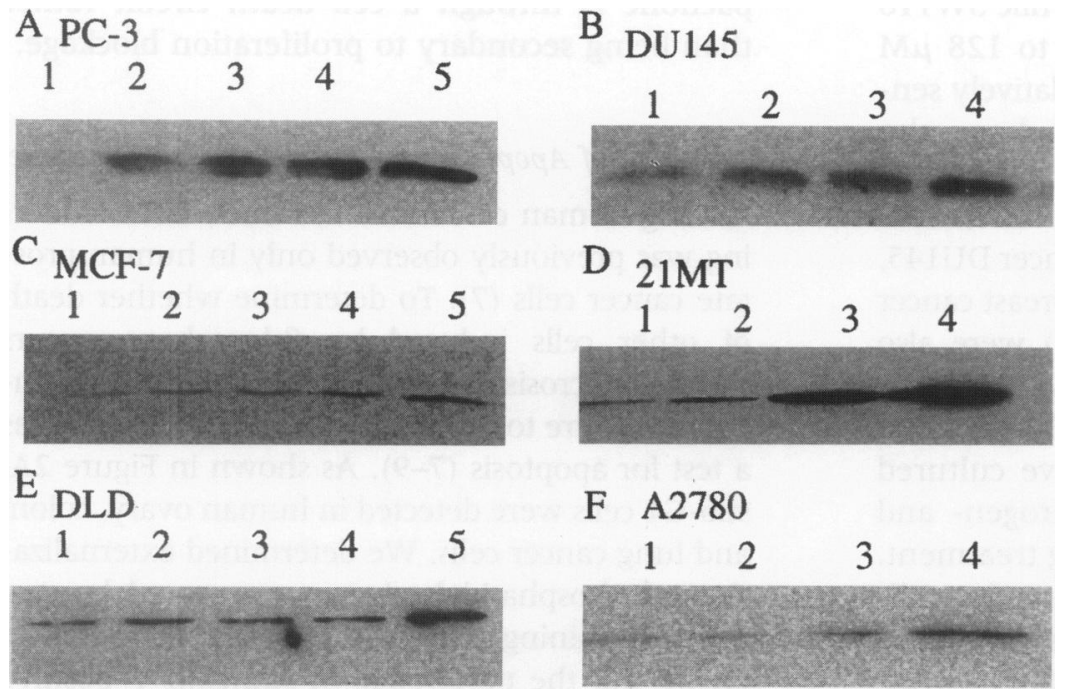

Fig. 3. Cell death induced by $\beta$-lapachone is accompanied by mitochondrial cytochrome $C$ release. (A) PC-3 cells were treated with DMSO (lane 1) or $\beta$-lapachone at $8 \mu \mathrm{M}$ for $0.5 \mathrm{hr}$ (lane 2), $2 \mathrm{hr}$ (lane 3), $4 \mathrm{hr}$ (lane 4), and $6 \mathrm{hr}$ (lane 5). (B-F), Cells were treated for $1 \mathrm{hr}$ with DMSO (lane 1) or $\beta$-lapachone at $0.5 \mu \mathrm{M}$ (lane 2), $2 \mu \mathrm{M}$ (lane 3), 4 $\mu \mathrm{M}$ (lane 4), or $8 \mu \mathrm{M}$ (lane $5, \mathrm{C}$ and E). Mitochondrial cytochrome $\mathrm{C}$ release was determined by Western blot assay as described in Materials and Methods. 


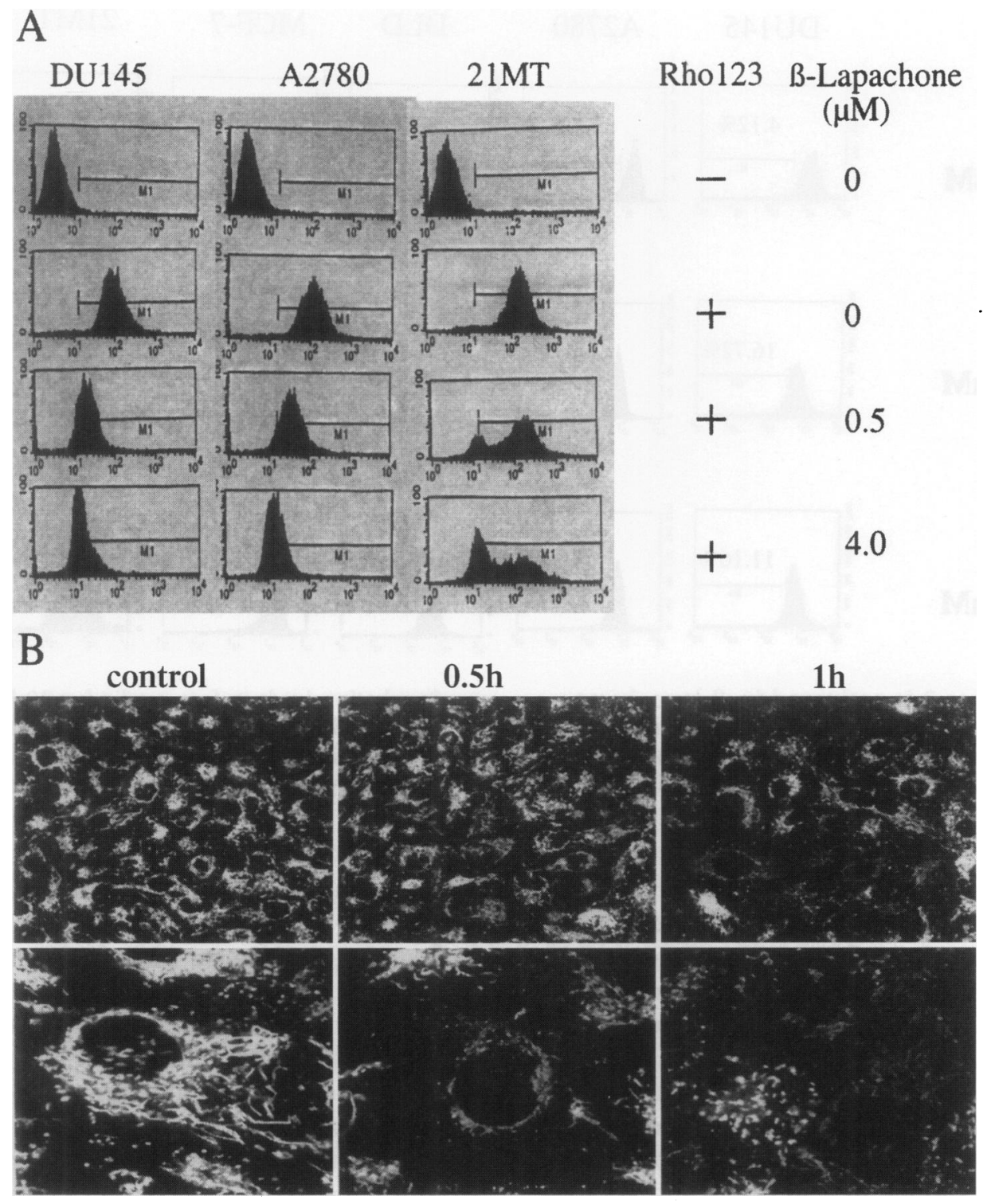

Fig. 4. Cytochrome $C$ release induced by $\beta$ lapachone is associated with decrease in mitochondrial membrane potential. Cells were stained with rhodamine 123 for $10 \mathrm{~min}$, followed by treatment with DMSO or $\beta$-lapachone at $0.5 \mu \mathrm{M}$ or $4 \mu \mathrm{M}$ for $4 \mathrm{hr}$, and then incubated in drug-free me-

Mitochondrial Cytochrome $C$ Release Induced by $\beta$ Lapachone Is Associated with Decrease in Mitochondrial Transmembrane Potential (Delta psi)

To investigate changes in mitochondria that resulted in cytochrome $C$ release, the mitochondrial membrane potential (delta psi) was analyzed by the accumulation of rhodamine 123 , a membranepermeant, cationic fluorescent dye (13). The rhodamine 123 fluorescence in mitochondria decreased shortly $(0.5 \mathrm{hr})$ after $\beta$-lapachone treatment, as analyzed by fluorescent microscopy dium for $20 \mathrm{hr}$. Fluorescence was determined by flow cytometry (A). DU145 cells were prestained with rhodamine 123 for $10 \mathrm{~min}$, followed by treatment with DMSO or $4 \mu \mathrm{M}$ of $\beta$-lapachone after 0.5 $\mathrm{hr}$ and $\mathrm{l} \mathrm{hr}$, then observed with fluorescent microscopy (B).

and flow cytometry (Fig. 4). This decrease in mitochondrial potential occurred not only in apoptotic cells (DU145 and A2780) but also in necrotic cells (21MT).

Activation of Caspase 3 in Apoptotic Cell Death, but Not in Necrotic Cell Death

We tested if cell death induced by $\beta$-lapachone involves activation of caspase 3 (CPP 32). As shown in Figure 5, caspase 3 was activated in 


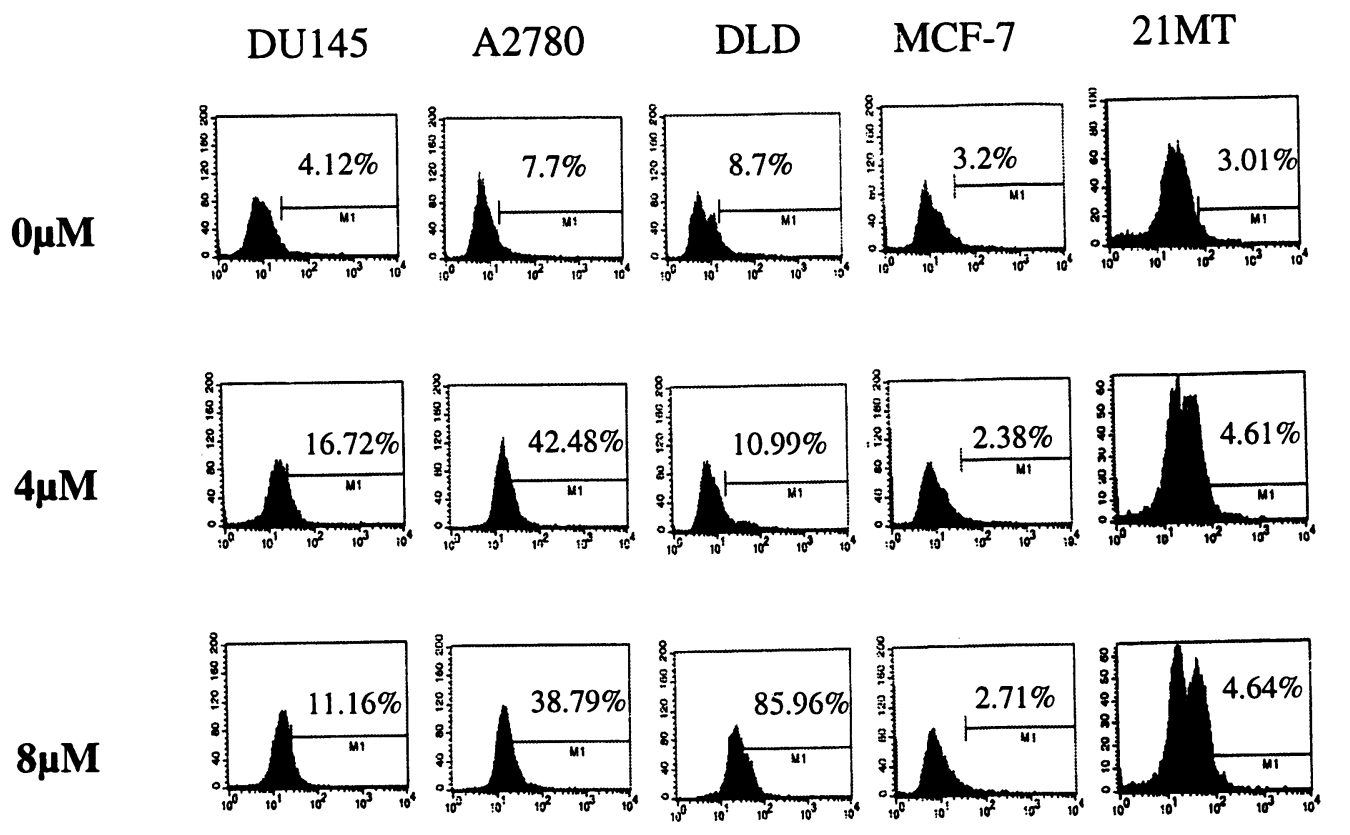

Fig. 5. Caspase 3 is activated in $\beta$-lapachoneinduced apoptotic cell death, but not in necrotic cell death. Cells were treated with DMSO or $\beta$-lapachone at $4 \mu \mathrm{M}$ or $8 \mu \mathrm{M}$ for $4 \mathrm{hr}$, followed by

$\beta$-lapachone-induced cell death in human prostate, ovary, colon, and lung cancer cells. This result suggests that the apoptosis induced by $\beta$-lapachone is through the activation of caspase 3. In contrast, there was no activation of caspase 3 in the four human breast cancer cell lines tested (two not shown). This lack of activation of CPP 32 in human breast cancer cells is consistent with the necrotic cell death induced by $\beta$-lapachone as determined by absence of sub-Gl fraction, externalization of phosphatidylserine.

\section{Discussion}

Both apoptosis and necrosis induced by $\beta$-lapachone are preceded by cytochrome $C$ release, suggesting that apoptosis and necrosis share common initiation pathways. $\beta$-lapachone treatment triggers a rapid release of cytochrome $C$ (within $0.5 \mathrm{hr}$ ), well before cell death was detected by other assays, suggesting that it is an early event in the course of both cell death processes induced by $\beta$-lapachone. The release of cytochrome $C$ in the early stage of necrosis suggests that necrosis is not a completely unregulated process. Two forms of cell death may share some molecular events. Further experiments are needed to shed light on the potential interaction

incubation in drug-free media for $20 \mathrm{hr}$. Cells were harvested and treated with the substrate, and intracellular caspase 3 activity was determined by flow cytometry as described in Materials and Methods.

between the apoptosis circuit and the necrotic process.

The mechanism of cytochrome $C$ release is unclear. $\beta$-lapachone might induce mitochondrial membrane permeability transition (PT), or perturb the outer mitochondrial membrane. Our experiment with rhodamine 123 showed that cytochrome $\mathrm{C}$ release is accompanied by the hypopolarization of the mitochondrial membrane. We failed to detect a transient hyperpolarization state as observed under some conditions that perturb the outer mitochondrial membrane (4). However, it is still unclear whether this transient hyperpolarization state truly exists or is an artifact of the experimental method (14). Our observation that overexpression of bcl-2 failed to prevent apoptosis induced by $\beta$-lapachone (8) further supports perturbation of the outer mitochondrial membrane as the mechanism.

The recently developed apoptosis assays, analyzing caspase activation and the externalization of phosphatidylserine, have allowed us to identify $\beta$-lapachone-induced cell death as involving apopotosis or necrosis. Our observation that $\beta$-lapachone induces necrotic cell death in MCF-7 cells is consistent with reports that this cell line lacks caspase 3 , owing to an inactivating deletion of nucleotides 54-178 within the coding region (15). Wuerzberger et al. recently reported 
that $\beta$-lapachone induces cell death of MCF-7 by apoptosis (16), on the basis of the presence of a population with DNA content of much less than $2 \mathrm{~N}$ at $48 \mathrm{hr}$ after drug treatment. We also observed a sub-Gl population by flow cytometry only after prolonged incubation subsequent to drug treatment. Our present study with more than one criterion for apoptosis demonstrates that this sub-Gl population is necrotic debris.

The wide-spectrum activity and novel mode of action make $\beta$-lapachone a potential anti-cancer agent. Apoptosis induced by $\beta$-lapachone through acting on the mitochondrial cytochrome $C$-caspase process is consistent with the observation that $\beta$-lapachone-induced cell death is not affected by p 53 status $(7,8)$. Thus, prevalent mutations in $p 53$ genes in human tumors are not expected to affect their sensitivity to $\beta$-lapachone. Alterations in the biochemistry of mitochondria have been associated with cell carcinogenic transformation phenotypes (13). Our results suggest mitochondrial membrane as a potential target for anti-cancer drug. Our earlier in vitro anti-cancer activity of $\beta$-lapachone in prostate cancer cells has been confirmed in animal experiments (Li et al., unpublished results). Further experiments are needed to test its in vivo effects on other types of cancer.

\section{Acknowledgment}

This work was supported in part by RO1CA61253 from the National Institute of Health.

\section{References}

1. Raffray M, Cohen GM. (1997) Apoptosis and necrosis in cytoxicology: a continuum or distinct modes of cell death? Pharmacol. Ther. 75: 153-177.

2. Nicholson DW, Ali A, Thornberry NA et al. (1995) Identification and inhibition of the ICE/CED-3 protease necessary for mammalian apoptosis. $\mathrm{Na}$ ture 376: 37-43.

3. Liu X, Kim CN, Yang J, Jemmerson R, Wang X. (1996) Induction of apoptotic program in cell-free extracts: requirement for dATP and cytochrome C. Cell 86: 147-157.
4. Green DR, Reed JC. (1998) Mitochondria and apoptosis. Science 281: 1309-1312.

5. Hooker SC. (1936) Lomatiol. Part II. Its occurrence, constitution, relation to and conversion into lapachol. Also, a synthesis of lapachol. J. Am. Chem. Soc. 58: 1181-1190.

6. Goncalves de Lima O, D'Albuquerque IL, Goncalves de Lima C, Dalia Maia MH. (1962) Substancias antimicrobianas de plantas superiores. Rev. Inst. Antibiot. Univ. Recife 4: 3-17.

7. Planchon SM, Wuerzberger S, Frydman B, et al. (1995) $\beta$-lapachone-mediated apoptosis in human promyelocytic leukemia (HL-60) and human prostate cancer cells: a p53 independent response. Cancer Res. 55: 3706-3711.

8. Li CJ, Wang C, Pardee AB. (1995) Induction of apoptosis by beta-lapachone in human prostate cancer cells. Cancer Res. 55: 3712-3715.

9. Li CJ, Friedman DJ, Wang C, Metelev V, Pardee AB. (1995) Induction of apoptosis in uninfected lymphocytes by HIV-1 tat protein. Science 268: 429-431.

10. Zhang G, Gurtu V, Kain SR, Yan G. (1997) Early detection of apoptosis using a fluorescent conjugate of annexin V. BioTechniques 23: 525-531.

11. Zou H, Henzel WJ, Liu X, Lutschg A, Wang X. (1997) Apaf-1, a human protein homologous to $C$. elegans CED-4, participates in cytochrome C-dependent activation of caspase-3. Cell 90: 405-413.

12. Packard BZ, Toptygian DD, Komoriya A, Brand L. (1996) Profluorescent protease substrates: intramolecular dimers described by the exciton model. Proc. Natl. Acad. Sci. U.S.A. 93: 1164011645.

13. Vander Heiden MG, Chandel NS, Williamson EK, Schumacker PT, Thompson CB. (1997) Bcl-xL regulates the membrane potential and volume homeostasis of mitochondria. Cell 91: 627-637.

14. Metivier D, Dallaporta B, Zamzami N, et al. (1998) Cytofluorometric detection of mitochondrial alterations in early CD95/Fas/APO-1-triggered apoptosis of Jurkat T lymphoma cells. Comparison of seven mitochondrion-specific fluorochromes. Immunol. Lett. 61: 157-163.

15. Janicke RU, Ng P, Sprengart ML, Porter AG. (1998) Caspase-3 is required for alpha-fodrin cleavage but dispensable for cleavage of other death substrates in apoptosis. J. Biol. Chem. 273: 15540-15545.

16. Wuerzberger SM, Pink JJ, Planchon SM, Byers KL, Bornmann WG, Boothman DA. (1998) Induction of apoptosis in MCF-7:WS8 breast cancer cells by beta-lapachone. Cancer Res. 58: 1876-1885. 